\title{
Reducing loss in practical single ring antiresonant hollow core fibres
}

\author{
J .R. Hayes, F. Poletti, D. J. Richardson \\ Optoelectronics Research Centre, University of Southampton, SO17 1BJ UK
}

Fibres that guide light in a large hollow core and in a single spatial mode are becoming increasingly important in the delivery of multi-MW peak power beams and to exploit nonlinear dynamics in gases. For high peak power beam delivery a large air core can prevent fibre damage and catastrophic self-focusing effects. Current hollow core fibre (HCF) types include photonic band gap (PBG) and Kagome fibres which rely on a periodically structured and therefore complex and extended cladding [1,2]. A simplified HCF fibre with a single antiresonant glass ring around the core and low loss at yellow wavelengths was recently reported [3]. Here we present an improved fibre design with a lower minimum loss (below $1 \mathrm{~dB} / \mathrm{m}$ ) in the near infrared. Stable drawing conditions allow the repeatable fabrication of long lengths of fibre.

By stacking 6 thin capillaries inside an outer tube and using a two-step drawing process we fabricated various HCFs. The SEM of an initial fibre with a Star of David $(\mathrm{SoD})$ structure and a close up of the thickened glass nodes where support struts join the core surround are shown in Fig.1a and b) respectively. The core diameter is $30 \mu \mathrm{m}$ and the thickness of the core surround is $440 \mathrm{~nm}$. The measured loss of this fibre was higher than expected for such a core diameter $(2 \mathrm{~dB} / \mathrm{m}$ in the visible). To understand why, we compared the numerically calculated confinement loss of an ideal SoD fibre without nodes to that of fibres with increasingly larger nodes, obtained by artificially rounding each vertex of the air holes. Simulations showed a strong correlation between larger nodes and higher losses. The calculated loss of the SoD fibre without nodes was found to be even lower than that of an ideal tubular fibre at some favoured wavelengths, although with some unavoidable spectral fluctuations due to coupling with 'whispering gallery' like modes (Fig. 2).
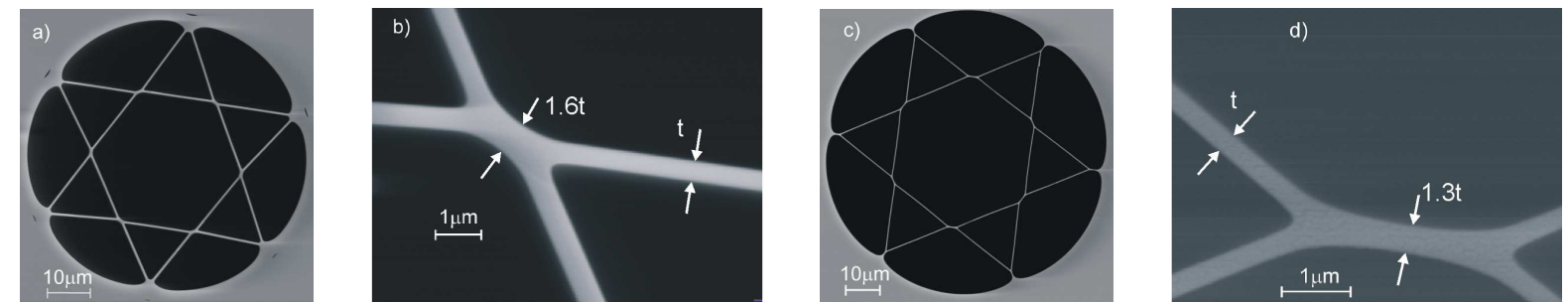

Fig. 1. Electron micrographs of a) initial fibre structure, b) node of initial fibre, c) structure of improved fibre, and d) node of improved fibre.

An improved fibre (Fig. 1c) was then drawn with increased cane expansion which elongated and reduced the thickness of the nodes (Fig. 1d). Core diameter and surround thickness were $39 \mu \mathrm{m}$ and $300 \mathrm{~nm}$ respectively. The measured loss shows several sub- $3 \mathrm{~dB} / \mathrm{m}$ regions between $0.8-1.5 \mu \mathrm{m}$, with a minimum of $0.9 \mathrm{~dB} / \mathrm{m}$ near $1.23 \mu \mathrm{m}$ (Fig. 3). With careful launch, transmission in a stable single Gaussian like mode was observed. The ultimate loss limit and potential applications of these promising new fibres will be discussed in more detail at the conference.

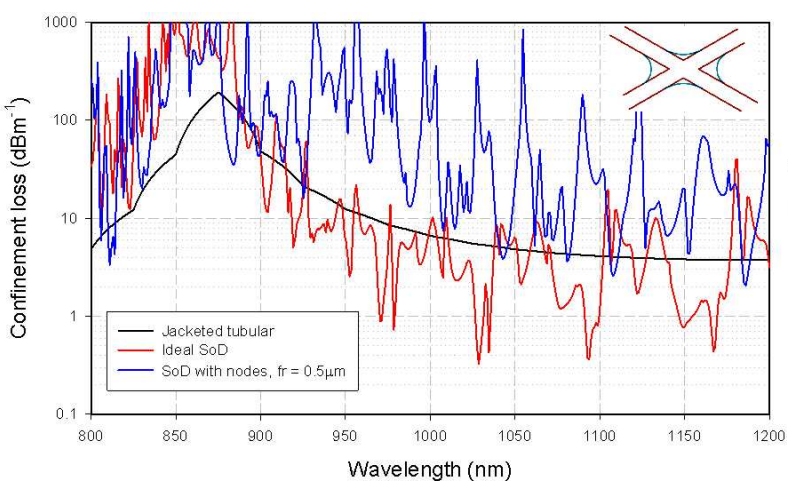

Fig. 2. Calculated confinement loss for the structures described in the text (core diameter $=30 \mu \mathrm{m}$, thickness $=420 \mathrm{~nm}$ ) and (insert) creation of nodes using a fillet radius fr.

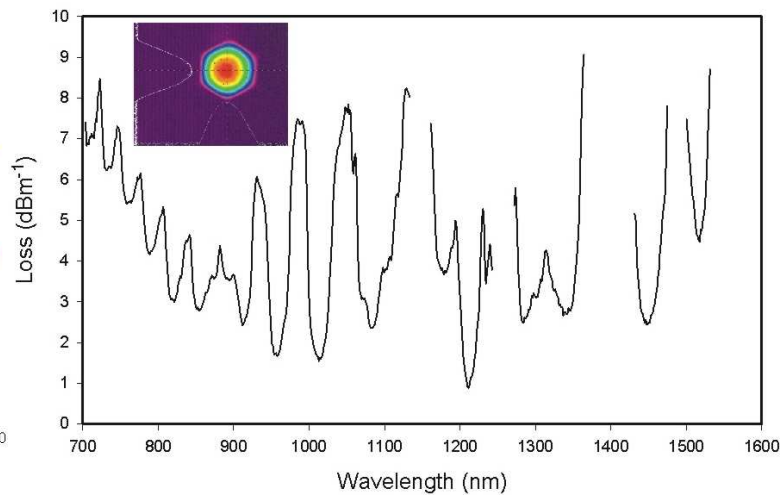

Fig. 3. Measured loss of the improved fibre in Fig.1c and (insert) image of the transmitted mode after $2 \mathrm{~m}$ of fibre.

\section{References}

[1] R. Cregan, B. Mangan, J. Knight, T. Birks, P. Russell, P. Roberts, and D. Allan,”Singlemode photonic band gap guidance of light in air," Science 285(5433), 1537 (1999)

[2] F. Couny, F. Benabid, and P. S. Light,’Large-pitch kagome-structured hollow-core photonic crystal fiber," Opt. Lett. 31, 3574 (2006).

[3] F. Gerome, R. Jamier, J. Auguste, G. Humbert, and J.Blondy, "Simplified hollow-core photonic crystal fiber," Opt. Lett. 35, 1157 (2010). 